\title{
Phenolic profiles of quince (Cydonia oblonga Mill.) leaf extracts obtained by different extraction methods
}

\author{
Martina Persic ${ }^{\star}$, Robert Veberic, Maja Mikulic-Petkovsek \\ Agronomy Department, Chair for Fruit, Vine and Vegetable Growing, Biotechnical Faculty, University of Ljubljana, \\ Ljubljana, Slovenia
}

\begin{abstract}
Extracts from quince leaves are a well-known home remedy used for treating diverse health problems. Most of the beneficial properties of quince leaf extracts may be assigned to their high content of phenolic compounds, particularly tannins. In this research, we have evaluated the efficiency of various methods for phenolic extraction from quince leaves and determined detailed phenolic profiles of different extracts. The results indicated that leaf drying is a suitable pretreatment for enhancing the extraction of phenolic compounds. Higher extraction of phenolics was achieved at higher temperatures (i.e. infusion or decoction). Phenolic profiles of quince leaf extracts differed among the extraction solvents and time of extraction. Flavanols prevailed in extracts obtained by decoction and ethanolic maceration, while extracts obtained by maceration in water and infusion were rich in phenolic acids. A highly concentrated quince leaf extract was attained by ethanolic maceration, using a standard ratio of solvent and leaf material.
\end{abstract}

Keywords: decoction, infusion, maceration, phenolics, quince, tannins

\section{Introduction}

Quince (Cydonia oblonga Mill.) trees are traditionally grown in private Mediterranean gardens as ornamental and utilitarian trees. The quince fruit resembles an apple or a pear in its shape, is highly aromatic, firm and rich in tannins (Lim 2012). The latter make the fruit inedible in its raw stage and therefore quince fruit is usually used for jam, marmalade, compote and in the production of juices, liqueurs and schnapps. Additionally, quince fruit, seeds and leaves possess healing and health beneficial properties (Khoubnasabjafari and Jouyban 2011). In comparison to the fruit, quince leaves are characterized by fivefold higher content of total phenolics, a threefold higher content of polymeric proantocyanidins, a sixfold higher content of mono-, di- and oligomeric flavan-3-ols, a 14-fold higher content of phenolic acids and a 13-fold higher content of flavonols (Teleszko and Wojdyło 2015). In traditional medicine, an infusion or decoction of dry quince leaves is often used to relieve problems of the gastrointestinal tract. The use of decoctions, hydro-ethanolic extracts and infusions of quince leaves is also recommended for their antidiabetic, antioxidant, antihemolytic and antihyperglycemic properties (Sajid et al. 2015). The antidiarrheal properties of quince leaf infusion, widely used in home remedies, can be attributed to the exceptionally high tannin content (11\%) of quince leaves ( $\operatorname{Lim} 2012)$.

Tannins are usually defined as phenolics with a high degree of polymerization. Condensed tannins are oligomers and polymers of flavanols linked with C-C bonds (Schofield et al. 2001) that are often found in the peel and pulp of different fruits. A shared feature of condensed and hydrolyzed tannins (so-called "true tannins") is the precipitation of proteins. The group of "pseudo tannins" encompasses molecules of lower molecular weight $\left(<500 \mathrm{~g} \mathrm{~mol}^{-1}\right)$ with low or no protein precipitating properties (Theisen et al. 2014). The term "pseudo-tannins" derives from the astringent, tannin-like taste of these compounds (Okuda et al. 1985). This group is formed from esters of hydroxycinnamic acids (chlorogenic, caffeic, ferulic and $p$-coumaric acid), monomeric flavanols ((epi)catechin, (epi)gallocatechin) and building blocks of hydrolyzed tannins (gallic and ellagic acid). Moreover, "pseudo-tannins" can be species- or genusspecific tannins (e.g. hamamelitannin from Hamamelis virginiana L. or ipecacuanhic acid from Carapichea ipecacuanha (Brot.) (Theisen et al. 2014).

\footnotetext{
* Corresponding author e-mail: martina.persic@bf.uni-lj.si
} 
Tannins have both positive and negative effects on human health. The consumption of tannin-rich foods could decrease the nutrient conversion efficiency in the digestive system (Chung et al. 1998). On the other hand, studies report antimutagenic, anticarcinogenic, anti-inflammatory and other health-beneficial properties of tannins (Dai and Mumper 2010).

In this research detailed phenolic profiles of various quince leaf extracts were evaluated. Extracts were obtained with decoction, maceration and infusion and all were prepared in a traditional way from fresh and dried quince leaves. Cold, ultrasound assisted extraction was used as a standard reference method for laboratory extraction. The extracts were compared based on their phenolic profiles, as phenolics represent the main bioactive, health-beneficial compounds in quince leaf extracts. To our knowledge this is the first study that compares the detailed phenolic profiles of various extracts of quince leaf produced from uniform material in uniform conditions.

\section{Materials and methods}

\section{Materials}

Leaves were sampled from five-year-old 'Champion' cultivar quince trees grown in a private garden in Rijeka, Croatia. Leaves were collected on the 25th of July 2016, transported in a portable icebox to the laboratory of the Biotechnical Faculty in Ljubljana, Slovenia and immediately processed.

\section{Methods}

Prior to final assessment, test extractions were performed. Different durations of maceration, decoction and infusion were tested. The adequate solvent to material ratios were acquired from the examination of traditional recipes and European Pharmacopoeia (Council of Europe 2007). A portion of fresh quince leaves was dried in an oven at a constant temperature of $40^{\circ} \mathrm{C}$ for $24 \mathrm{~h}$. Average water content of dry material for infusion and decoction was $28.2 \%$. The remaining part of fresh quince leaves was used for fresh leaf extraction.

\section{Maceration}

Fresh quince leaves were de-stemmed and cut into small pieces. A mass of $2 \mathrm{~g}$ fresh quince leaves was extracted in $25 \mathrm{~mL}$ of $100 \%$ ethanol $(\mathrm{Mac} \mathrm{EtOH})$ or water $\left(\mathrm{Mac} \mathrm{H}_{2} \mathrm{O}\right)$, respectively. Maceration was carried out at room temperature in sealed containers for $24 \mathrm{~h}$.

\section{Infusion and decoction}

Half of gram of dried quince leaves was infused in $100 \mathrm{~mL}$ of distilled water. Water was heated to the boiling point and immediately poured over the dried material in $250 \mathrm{~mL}$ beakers, which were then covered with Petri dish. The leaves were left to extract for 15 minutes. Decoction was conducted on $1 \mathrm{~g}$ of fresh (Dec F) and $0.5 \mathrm{~g}$ of dried (Dec D) material. The material was boiled for 15 minutes in $100 \mathrm{~mL}$ (dry leaves) or $150 \mathrm{~mL}$ (fresh leaves) of distilled water. After decoction, the extract was left to cool down for 5 minutes. During boiling, the volume of water evaporated to $50 \%$ of the initial level.

Cold, ultrasound assisted extraction

The procedure was carried out according to the standard protocol for polyphenolic extraction in our laboratory (Persic et al. 2018a; Persic et al. 2017) with slight modifications. Fresh quince leaves were de-stemmed and cut into small pieces. Exactly $2 \mathrm{~g}$ of leaf material was placed into 10 $\mathrm{mL}$ centrifuge tubes and topped up with $25 \mathrm{~mL}$ of ethanol (EtOH US) or $25 \mathrm{~mL}$ of water ( $\mathrm{H}_{2} \mathrm{O}$ US). Tubes were subsequently deposited into an ice filled Sonis 4 GT ultrasonic water bath (Iskra PIO, Šentjernej, Slovenia) and extracted for $1 \mathrm{~h}$ at $50 \mathrm{~Hz}$.

\section{Phenolic compounds analysis by HPLC-MS}

After various extraction procedures, the samples were centrifuged and filtrated through $0.20 \mu \mathrm{m}$ Chromafil AO20/25 polyamide filters (Macherey-Nagel, Düren, Germany) into vials. The samples were further analyzed by the protocol described in Persic et al. (2018). The determination of individual phenolics was carried out on a Thermo Finnigan Surveyor high-performance liquid chromatography system (HPLC, Thermo Fisher Scientific, Waltham, USA). Phenolics were further identified on a mass spectrometer (MS, Thermo Fisher Scientific) with electrospray ionization (ESI) operating in negative ion mode. The concentration of individual phenolic compounds was calculated from corresponding calibration curves of standard solutions; procyanidin B1, catechin, epicatechin, $p$-coumaric acid, caffeic acid, 3-caffeoylquinic acid (3CQA), 4-caffeoylquinic acid (4CQA), 5-caffeoylquinic acid (5CQA), quercetin-rutinoside, quercetin-galactoside, quercetin-glucoside, quercetin-rhamnoside, kaempferol-glucoside and isorhamnetin-glucoside.

All extractions were carried out in six replicates (five leaves per replicate). The concentration of phenolic compounds in samples was calculated per dry matter in order to enable accurate comparison of extracts processed from partially dry (Inf and Dec D) and fresh material (EtOH US, $\mathrm{H}_{2} \mathrm{O}$ US, Mac EtOH, Mac $\mathrm{H}_{2} \mathrm{O}$ and Dect F). Ultrasound assisted extraction was used as a reference method for efficient extraction of phenolic compounds.

\section{Statistical analysis}

The Statgraphics Plus 4.0 program (Manugistics. Inc.; Rockville, Maryland, USA) was used for data analysis. Significant differences in the concentration of individual phenolics, phenolic groups, total analyzed phenolics and total phenolics concentration among extracts were tested using one way analysis of variance (ANOVA). Duncan's test was used to calculate significant differences in the concentration of phenolics among the different extraction procedures. P-values lower than or equal to 0.05 were considered statistically significant. In the graphs, significant differences among values are denoted by different letters. For graphic interpretation of the results, a heat map was plotted in R-Commander using 
the gplot package (R Formation for Statistical Computina, Anckland, New Zeland) based on standardised data $(\mu=0$, $\sigma=1$ ). Ward's method based on the square Euclidian distance was used for hierarchical cluster analysis and grouping of varieties according to their individual phenolic compounds.

\section{Results and discussion}

The optimum maceration time was $24 \mathrm{~h}$ and the optimum duration for quince leaf infusions and decoctions was 15 minutes. In all, twenty-nine phenolic compounds, belonging to the groups of flavanols, flavonols and phenolic acids, were identified and quantified in the extracts of quince leaves analyzed. In all quince extracts analyzed, the group of flavonols is composed of seven derivatives of kaempferol, four derivatives of quercetin, and isorhamnetin pentoside (Fig. 1, On-line Suppl. Tab. 1). Quercetin-rutinoside is most dominating flavonol in all quince leaf extracts except Dec F, whose flavonol profile is dominated by quercetin-galactoside (Fig. 2). The distinct grouping of ethanolic and water extract based on Ward's method with squared Euclidean distance is also observable in Fig. 1. Additionally, it is noticeable that the decoction of fresh material (Dec F) has the most distinctive flavanol profile with quercetin-galactoside, kaempferolglucoside and kaempferol-rhamnosylhexoside IV as its main constituents. The distinctive grouping of ethanolic extracts is probably due to the lower content of all kaempferol-rhamnosylhexoside isomers in comparison to other extracts.

The overall highest concentration of flavonols from quince leaves was achieved by the decoction of dry quince leaves $\left(5.4 \pm 0.5 \mathrm{~g} \mathrm{~kg}^{-1} \mathrm{DW}\right)$ and by ethanolic maceration $\left(4.7 \pm 0.3 \mathrm{~g} \mathrm{~kg}^{-1} \mathrm{DW}\right)$ (Fig. 2, On-line Suppl. Tab. 1). Significantly lower concentration of flavonols was detected in samples acquired with US in ethanol $\left(3.1 \pm 0.1 \mathrm{~g} \mathrm{~kg}^{-1} \mathrm{DW}\right)$, infusion $\left(3.5 \pm 0.3 \mathrm{~g} \mathrm{~kg}^{-1} \mathrm{DW}\right)$ and decoction of fresh material $\left(2.7 \pm 0.2 \mathrm{~g} \mathrm{~kg}^{-1} \mathrm{DW}\right)$. The lowest concentration of flavonols was determined in extracts prepared with cold $\left(\mathrm{H}_{2} \mathrm{O}\right.$ US) and room temperature $\left(\mathrm{Mac}_{2} \mathrm{O}\right)$ extractions in water. High flavonol levels are typical of phenolic extracts from leaves since these compounds play an important role in protection against excessive UV radiation (Jakopic et al. 2009). Similar results in alcoholic extraction of phenolics from apple leaves were acquired by Jakopic et al. (2009).

The group of phenolic acids in quince leaves is composed of seven caffeoylquinic (CQA) derivatives and five coumaric acid derivatives (Fig. 3, On-line Suppl. Tab. 2). In contrast to earlier findings, we have identified five additional derivatives of coumaric acid in this species' leaves; additional isomers of 3CQA, 5CQA, 5-coumaryilquinic acid and $p$ - cumaric acid hexoside (Costa et al. 2009, Oliveira et al. 2007, Teleszko and Wojdyło 2015).

5CQA is the most abundant phenolic acid in all extracts except Dec F. It is interesting that combined content of 3CQA and 5CQA I represented as much as $85 \%$ of all analyzed phenolic acids in water infusion. Furthermore, caffetannins in quince leaf infusion encompass 3CQA, 4CQA, 5CQA I,

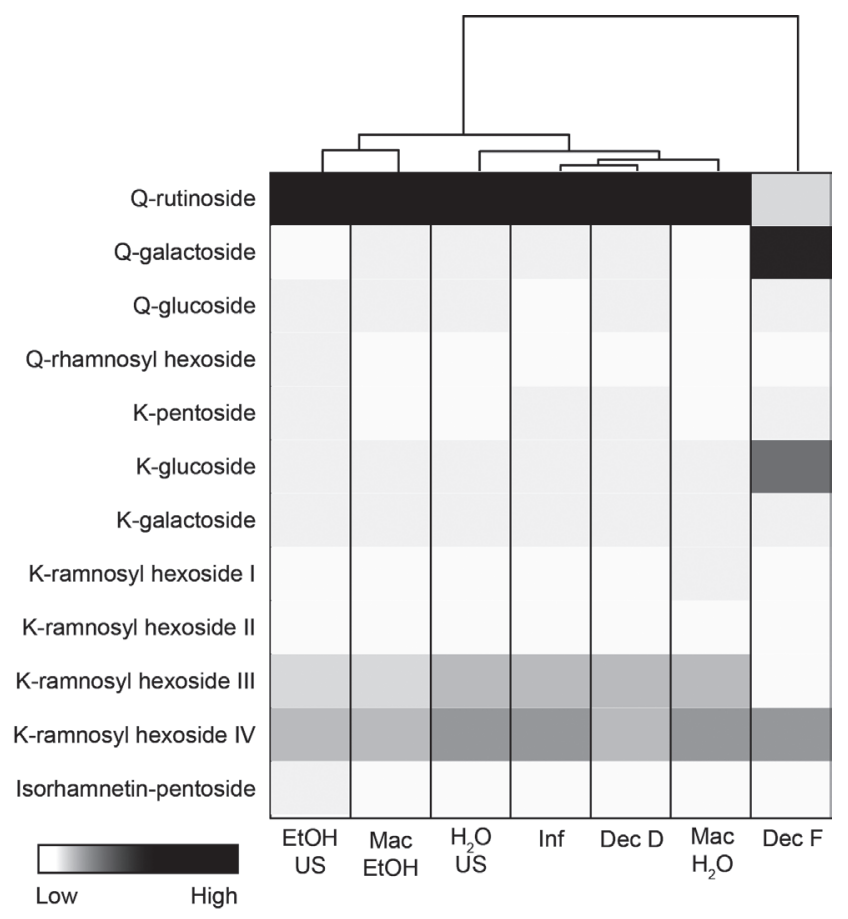

Fig. 1. The flavonol profile in various quince leaf extracts; ultrasound extraction in water $\left(\mathrm{H}_{2} \mathrm{O}\right.$ US), ultrasound extraction in ethanol (EtOH US), water maceration $\left(\mathrm{Mac}_{2} \mathrm{O}\right)$, ethanolic macerate $(\mathrm{Mac} \mathrm{EtOH})$, water infusion (Inf), decoction of dry material (Dec D) and decoction of fresh material (Dec F). The data are standardised $(\mu=0, \sigma=1)$, low values are presented with light colors, higher values are presented with dark colors. Q-quercetin, K-kaempferol.

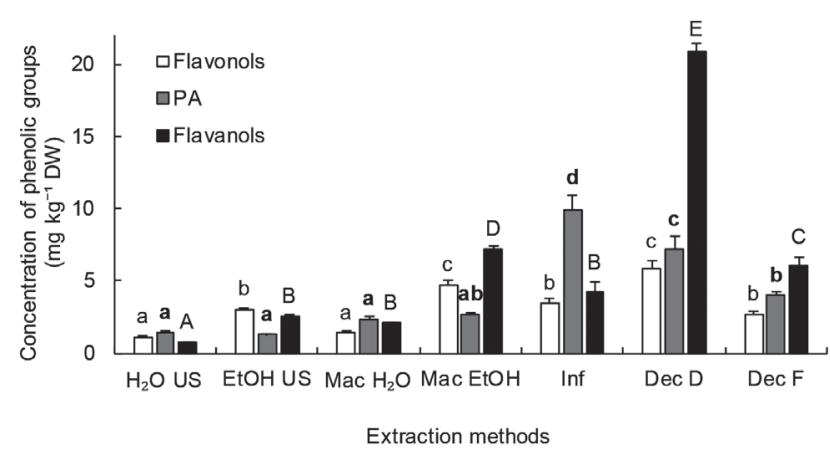

Fig. 2. Concentration of the phenolic groups (flavonols, phenolic acids (PA) and flavanols) in various extracts from quince leaves; ultrasound extraction in water $\left(\mathrm{H}_{2} \mathrm{O}\right.$ US), ultrasound extraction in ethanol (EtOH US), water maceration $\left(\mathrm{Mac}_{2} \mathrm{O}\right)$, ethanolic macerate $(\mathrm{Mac} \mathrm{EtOH})$, water infusion (Inf), decoction of dry material (Dec D) and decoction of fresh material (Dec F). The comparison was made regarding phenolic group, for each extract separately. Lowercase letters ( $a, b$, etc.) indicate significant differences among concentration of flavonols in various extracts, bold lowercase letters $(\mathbf{a}, \mathbf{b}$, etc.) indicate significant differences among concentration of PA in various extracts, while uppercase letters (A, B, etc.) stand for significant differences among the concentration of flavanols in various extracts; determined by the Duncan test $(\mathrm{p}<0.05)$. Standard error is presented with error bar. 


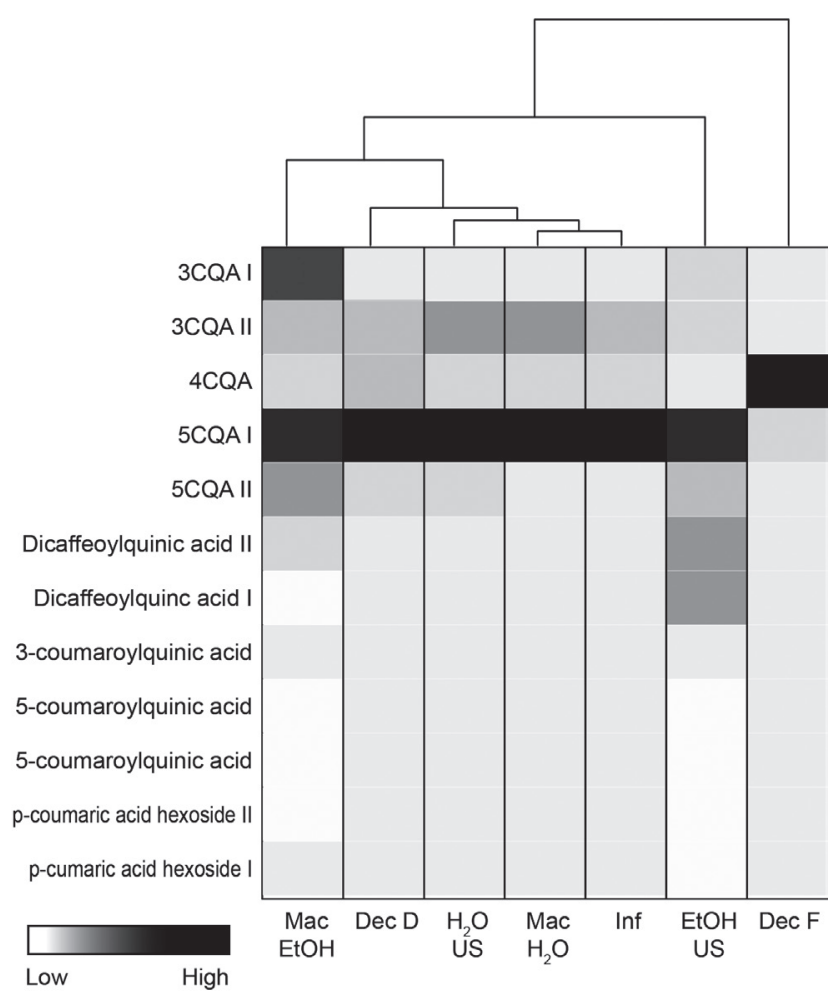

Fig. 3. The profile of phenolic acids in various extracts from quince leaves; ultrasound extraction in water $\left(\mathrm{H}_{2} \mathrm{O}\right.$ US), ultrasound extraction in ethanol (EtOH US), water maceration $\left(\mathrm{Mac}_{2} \mathrm{O}\right)$, ethanolic macerate (Mac EtOH), water infusion (Inf), decoction of dry material (Dec D) and decoction of fresh material (Dec F). The data are standardised $(\mu=0, \sigma=1)$, low values are presented with light colors, higher values are presented with dark colors. CQA - caffeoylquinic acid.

5CQA II and dicaffeoylquinic acid I, and represent 95\% of all identified phenolic acids and more than $50 \%$ of total analyzed phenolics in all analyzed extracts from quince leaves.

Grouping of various extracts regarding the profile of phenolic acids showed significant separation of Dec F and EtOH US extracts. The separation of Dec F from the rest of analyzed extracts is due to its lower concentration of 5CQA and significantly higher concentration of 4CQA. Meanwhile, the separation of extract obtained by ultrasound extraction in ethanol (EtOH US) is mainly based on the higher concentration of isomers of dicaffeoylquinic acid and lower concentration of the derivatives of coumaroylquinic and coumaric acid. Regarding the specific extractability of individual phenolic acids in various solvents, 5CQA II was better extracted in ethanol, while 3CQA was better extracted in water.

Overall, the highest total concentrations of analyzed phenolic acids were measured in samples prepared with water infusion Inf $\left(9.9 \pm 1.0 \mathrm{~g} \mathrm{~kg}^{-1} \mathrm{DW}\right)$ followed by Dec D (7.3 \pm $\left.0.8 \mathrm{~g} \mathrm{~kg}^{-1} \mathrm{DW}\right)$, Dec F $\left(4.0 \pm 0.3 \mathrm{~g} \mathrm{~kg}^{-1} \mathrm{DW}\right)$, both macerations ( $\mathrm{Mac}$ EtOH and $\mathrm{Mac} \mathrm{H}_{2} \mathrm{O}$ ) and finally, US extractions (EtOH US, $\mathrm{H}_{2} \mathrm{O}$ US) (Fig. 2, On-line Suppl. Tab. 2). Additionally, the highest ratio of phenolic acids in comparison to other phenolic groups was detected in water extractions preformed at temperatures below the boiling point.
Meanwhile, the highest concentration of flavanols was achieved using a decoction of dry material (Dec D $20.8 \pm$ $0.6 \mathrm{~g} \mathrm{~kg}^{-1} \mathrm{DW}$ ), followed by maceration in ethanol (Mac EtOH $7.2 \pm 0.3 \mathrm{~g} \mathrm{~kg}^{-1} \mathrm{DW}$ ), decoction of fresh leaves (Dec F $\left.6.1 \pm 0.5 \mathrm{~g} \mathrm{~kg}^{-1} \mathrm{DW}\right)$ and water infusion (Inf $4.2 \pm 0.7 \mathrm{~g}$ $\mathrm{kg}^{-1} \mathrm{DW}$ ) (Fig. 2).

Significant variability in the efficiency of extraction of individual flavanols was detected among the extraction methods. Epicatechin and procyanidin trimer II accounted for more than $50 \%$ of all analyzed flavanols in the various analyzed extracts from quince leaves. Extractability of procyanidin trimer II was generally higher in water than in ethanol, and at lower rather than at higher temperatures (Fig. 4, Online Suppl. Tab. 3). Extraction of catechin from quince leaves was higher at higher temperatures, while catechin was dominant only in extracts acquired by the decoction of dry material. These results are compatible with previous findings on the solubility of phenolic compounds described by MikulicPetkovsek et al. (2015). The higher concentration of epicatechin in Inf, Dec D, EtOH US, and in Mac EtOH can be explained through degradation of phenolic compounds during drying of plant material before extraction for Inf and Dec D, while ethanol could play an important part in the degradation of oligomeric to monomeric flavanols in $\mathrm{EtOH}$ US and Mac EtOH. The grouping of extracts using Ward's method with square Euclidian distance showed separation of analyzed extracts based on the content of epicatechin (Fig. 4).

The highest level of total analyzed phenolics was detected in samples prepared with decoction of dry material (Dec D $34.7 \pm 1.2 \mathrm{~g} \mathrm{~kg}^{-1}$ DW) (Suppl. Fig. 1). A lower content of total analyzed phenolics was measured in extracts in the following order: infusion of dried leaves Inf $\left(17.6 \pm 1.9 \mathrm{~g} \mathrm{~kg}^{-1}\right.$ DW $)>\mathrm{Mac}$ EtOH $\left(14.6 \pm 2.2 \mathrm{~g} \mathrm{~kg}^{-1} \mathrm{DW}\right)>\mathrm{Dec} \mathrm{F}(12.8 \pm$ $\left.0.8 \mathrm{~g} \mathrm{~kg}^{-1} \mathrm{DW}\right)>\mathrm{Mac} \mathrm{H}_{2} \mathrm{O}\left(5.8 \pm 2.7 \mathrm{~g} \mathrm{~kg}^{-1} \mathrm{DW}\right) \approx \mathrm{EtOH} \mathrm{US}$ $\left(6.8 \pm 0.2 \mathrm{~g} \mathrm{~kg}^{-1} \mathrm{DW}\right)>\mathrm{H}_{2} \mathrm{O}$ US $\left(3.3 \pm 0.2 \mathrm{~g} \mathrm{~kg}^{-1} \mathrm{DW}\right)$. As a rule, all extraction techniques (with the exception of water macerate) were more effective in extraction of phenolic compounds than standard laboratory methods (US extrac-

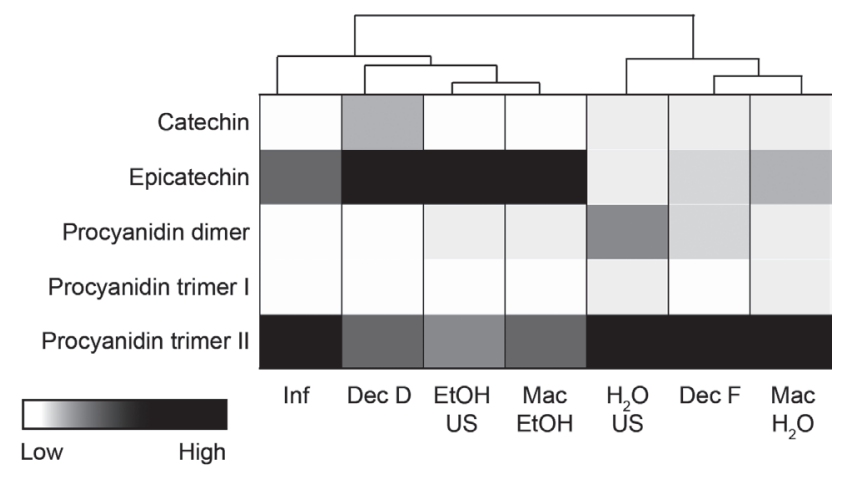

Fig. 4. The profile of flavanols in various extracts from quince leaves; ultrasound extraction in water $\left(\mathrm{H}_{2} \mathrm{O}\right.$ US), ultrasound extraction in ethanol (EtOH US), water maceration $\left(\mathrm{Mac}_{2} \mathrm{O}\right)$, ethanolic macerate $(\mathrm{Mac} \mathrm{EtOH})$, water infusion (Inf), decoction of dry material (Dec D) and decoction of fresh material (Dec F). The data are standardised $(\mu=0, \sigma=1)$, low values are presented with light colors, higher values are presented with dark colors. 
tions). Lower content of phenolic compounds in water macerate can partially be ascribed to the oxidation and degradation of phenolic compounds during $24 \mathrm{~h}$ extraction at room temperature (Khachatryan et al. 2005).

Among the analyzed extracts, $\mathrm{Mac} \mathrm{EtOH}$ is the most concentrated in terms of mass of phenolic compounds per liter of extract (951.9 $\left.\pm 8.5 \mathrm{mg} \mathrm{L}^{-1}\right)$ (On-line Suppl. Fig. 1). The lowest concentration of total analyzed phenolics was detected in Inf $\left(66.0 \pm 6.9 \mathrm{mg} \mathrm{L}^{-1}\right)$ and Dec F $\left(107.0 \pm 6.7 \mathrm{mg} \mathrm{L}^{-1}\right)$. The decoction obtained from dry material (Dec D $230.8 \pm 24.7 \mathrm{mg} \mathrm{L}^{-1}$ ) was twice as concentrated as the decoction obtained by fresh quince leaf processing $\left(91.6 \pm 5.5 \mathrm{mg} \mathrm{L}^{-1}\right)$. The difference in water content between fresh leaves and partially dried material was only $5.8 \%$ and therefore, lower concentration of phenolics in fresh leaf extracts cannot solely be explained by the variation in the initial water content. However, the higher concentration of phenolic compounds in Dec D than in Dec F may be explained by pretreatment of the material, i.e. $24 \mathrm{~h}$ drying at $45^{\circ} \mathrm{C}$. Additionally, Mokrani and Madani (2016) confirmed the significant effect of solvent type, temperature and time of maceration on the extraction of total phenolics.

Because of the differences in the extractability of phenolic compounds, substantial differences in the ratio among flavanols, phenolic acids and flavonols were detected in quince leaf extracts. The most noticeable differences in phenolic profiles were recorded between Inf and Dec D samples. The flavonols: phenolic acids: flavanols ratio in infusion was 1:3:1 and the ratio in Dec D was 1:1:3 (Fig. 2). In this research, the specific solubility of phenolic compounds and even isomers of the same molecule was observed in various solvents. This could be due to different polarity, which affects the solubility of isomeric molecules (Gaikar and Phatak 1999).

In addition to phenolic profiling of various quince leaf extracts, the aim of this research was to evaluate various ex- tracts based on their phenolic profile. Ethanolic extract (Mac $\mathrm{EtOH}$ ) was approx. 14-fold more concentrated than quince leaf water infusion. Additionally, the phenolic profiles of these two extracts differ significantly. Quince leaf infusion consists of $58 \%$ phenolic acids, $19 \%$ flavonols and $23 \%$ flavanols but, by contrast, an ethanolic macerate consists of $21 \%$ phenolic acids, $31 \%$ flavonols and $48 \%$ flavanols. On the other hand, water macerate $\left(\mathrm{Mac}_{2} \mathrm{O}\right)$ is comparable to quince leaf infusion (Inf). The former was characterized by an almost 6-fold more concentrated phenolic composition per liter of extract and a similar phenolic profile to that from the infusion. As little as $17 \mathrm{~mL}$ of water macerate (Mac $\mathrm{H}_{2} \mathrm{O}$ ) could replace $100 \mathrm{~mL}$ of infusion (Inf).

According to our results, pretreatment (i.e. drying) had a significant positive effect on the extractability of phenolic compounds from quince leaves. Abascal et al. (2005) reviewed the impact of drying on the extraction of phenolic compounds from various plant samples and concluded that there is no uniform effect of drying on phenolic extraction or on altered phenolic profiles of the extracts. To our knowledge, no previous findings report the differences in phenolic extraction from dried and fresh quince leaves.

In conclusion, our results demonstrate the poor efficiency of ultrasound assisted extraction for the extraction of quince leaf phenolic compounds compared to other examined methods. Drying followed by decoction of quince leaves stands out as the most favorable method for the extraction of polyphenolic compounds.

\section{Acknowledgements}

This work is part of the program Horticulture P40013-0481, supported by the Slovenian Research Agency (ARRS).

\section{References}

Abascal, K., Ganora, L., Yarnell, E., 2005: The effect of freeze-drying and its implications for botanical medicine: a review. Phytotherapy Research 19, 655-660.

Chung, K.T., Wong, T.Y., Wei, C.I., Huang, Y.W., Lin, Y., 1998: Tannins and human health: a review. Critical reviews in food science and nutrition 38, 421-464.

Council of Europe, 2007: European Pharmacopoeia. $6^{\text {th }}$ ed. Strasbourg, France: Council of Europe.

Costa, R.M., Magalhães, A.S., Pereira, J.A., Andrade, P.B., Valentão, P., Carvalho, M., Silva, B.M., 2009: Evaluation of free radical-scavenging and antihemolytic activities of quince $(C y$ donia oblonga) leaf: a comparative study with green tea $(\mathrm{Ca}$ mellia sinensis). Food and Chemical toxicology 47, 860-865.

Dai, J., Mumper, R.J., 2010: Plant phenolics: extraction, analysis and their antioxidant and anticancer properties. Molecules 15, 7313-7352.

Gaikar, V., Phatak, P., 1999: Selective solubilization of isomers in hydrotrope solutions: o-/p-chlorobenzoic acids and o-/p-nitroanilines. Separation Science and Technology 34, 439-459.

Jakopic, J., Stampar, F., Veberic, R., 2009: The influence of exposure to light on the phenolic content of 'Fujiapple. Scientia Horticulturae 123, 234-239.
Khachatryan, K.S., Smirnova, S.V., Torocheshnikova, I.I., Shvedene, N.V., Formanovsky, A.A., Pletnev, I.V., 2005: Solvent extraction and extraction-voltammetric determination of phenols using room temperature ionic liquid. Analytical and Bioanalytical Chemistry 381, 464-470.

Khoubnasabjafari, M., Jouyban, A., 2011: A review of phytochemistry and bioactivity of quince (Cydonia oblonga Mill.). Journal of Medicinal Plants Research 5, 3577-3594.

Lim, T.K., 2012: Edible medicinal and non-medicinal plants (Vol. 4) 1st ed. Rotterdam, Netherlands: Springer.

Mokrani, A., Madani, K. 2016: Effect of solvent, time and temperature on the extraction of phenolic compounds and antioxidant capacity of peach (Prunus persica L.) fruit. Separation and Purification Technology 162, 68-76.

Mikulic-Petkovsek, M., Samoticha, J., Eler, K., Stampar, F., Veberic, R., 2015: Traditional elderflower beverages: a rich source of phenolic compounds with high antioxidant activity. Journal of Agricultural and Food Chemistry 63, 1477-1487.

Okuda, T., Mori, K., Hatano, T., 1985: Relationship of the structures of tannins to the binding activities with hemoglobin and methylene blue. Chemical and Pharmaceutical Bulletin $33,1424-1433$. 
Oliveira, A.P., Pereira, J.A., Andrade, P.B., Valentão, P., Seabra, R.M., Silva, B.M., 2007: Phenolic profile of Cydonia oblonga Miller leaves. Journal of Agricultural and Food Chemistry 55, 7926-7930.

Persic, M., Mikulic-Petkovsek, M., Halbwirth, H., Solar, A., Veberic, R., Slatnar, A., 2018: Red walnut: Characterization of the phenolic profiles, and activity and gene expression of selected enzymes related to the phenylpropanoid pathway in pellicle during walnut development. Journal of Agriculture and Food Chemistry 66, 2742-2748.

Persic, M., Mikulic-Petkovsek, M., Slatnar, A., Veberic, R., 2017: Chemical composition of apple fruit, juice and pomace and the correlation between phenolic content, enzymatic activity and browning. Lwt-Food Science and Technology 82, 23-31.
Sajid, S.M., Zubair, M., Waqas, M., Nawaz, M., Ahmad, Z., 2015: A review on quince (Cydonia oblonga): a useful medicinal plant. Global Vetenaria 14, 517-524.

Schofield, P., Mbugua, D., Pell, A., 2001: Analysis of condensed tannins: a review. Animal Feed Science and Technology 91, 21-40.

Teleszko, M., Wojdyło, A., 2015: Comparison of phenolic compounds and antioxidant potential between selected edible fruits and their leaves. Journal of Functional Foods 14, 736-746.

Theisen, L.L., Erdelmeier, C.A., Spoden, G.A., Boukhallouk, F., Sausy, A., Florin, L., Muller, C.P., 2014: Tannins from Hamamelis virginiana bark extract: characterization and improvement of the antiviral efficacy against influenza A virus and human papillomavirus. PloS one 9, e88062. 